\title{
A Behavioral Archaeologist Responds
}

\author{
Michael Brian Schiffer
}

Published online: 21 June 2011

(C) Springer Science+Business Media, LLC 2011

\begin{abstract}
The final contribution to the 2010 Society for American Archaeology Forum, "Assessing Michael B. Schiffer and his Behavioral Archaeology," is Schiffer's response to issues raised by Michael J. O'Brien and Alexander Bentley, Robert L. Kelly, Linda S. Cordell, Stephen Plog, and Diane Gifford-Gonzalez in their published contributions. This paper addresses several long festering issues, reiterates and clarifies some positions, and presents a few unpublished views.
\end{abstract}

Keywords Behavioral Archaeology · Technological change · Invention · Diffusion · Formation processes

Let me begin by thanking J. Jefferson Reid and James M. Skibo, good friends and esteemed colleagues, for dreaming up and pulling off this unique experiment in archaeological communication. I am also grateful to the Forum's distinguished participants whose contributions have stimulated much thought and discussion. Needless to say, I have been touched by the warm and overly generous praise in these papers; they left me immensely appreciative and uncommonly speechless beyond a heartfelt "thank you." The highly varied contents of these papers resist thematic organization, and so I simply discuss them individually.

Michael J. O’Brien and Alexander Bentley

Not only did Mike and Alex deeply engage my work on invention processes, but they also crafted an original contribution of considerable merit. In view of the length and density of their paper, I can only cherry-pick issues.

In discussing cultural transmission processes, they showed how an evolutionary perspective can incorporate the behavioral constructs of stimulated variation and the cascade model of invention processes. This move adds weight to the claim that evolutionary and behavioral archaeologies are in many respects compatible (Schiffer 1996), yet behavioral and postprocessual archaeologies also enjoy major congruities (e.g., Hollenback 2010; Hollenback and Schiffer 2010; Schiffer and Miller 1999;

M. B. Schiffer $(\bowtie)$

School of Anthropology, University of Arizona, Tucson, AZ 85721, USA

e-mail: schifferma@gmail.com 
Skibo and Schiffer 2008, chapters 1 and 2; Walker and Schiffer 2006). Perhaps one day a Darwin or Marx of archaeology will come along and weave the varied strands of "social" theory (sensu Schiffer 1988) into one rich tapestry. In the meantime, we should continue to explore synergies between different programs.

Mike and other evolutionists have increasingly addressed cultural transmission processes (e.g., O'Brien 2008), a subject studied experimentally and ethnoarchaeologically by processualists and behavioral archaeologists but handled as "teaching" or "learning" frameworks (e.g., see references in Schiffer et al. 2001). Evolutionary archaeologists take a different tack, in some cases building formal models that quantify diffusionist constructs. These models rest on a flimsy foundation because central tenets of diffusion theory are erroneous, such as the belief that knowledge about a new behavior is a necessary and sufficient cause of its adoption (Schiffer 2008c). In most cases, far more people know about a new behavior than actually adopt it. Thus, one behavioral move is to explain a new behavior's differential adoption (Schiffer 2005a).

An even more serious defect in diffusion theory and its associated cultural transmission models is the tendency to conflate processes occurring during a technology's life cycle. Collapsing all change processes into "invention" and "innovation," for example, glosses over commercialization, which consists of development and manufacture processes (e.g., the latter is "replication" in evolutionary terms). In a behavioral framework, each process-invention, development, manufacture, and adoption-requires its own theories and models (Schiffer 2011).

A technology's life cycle is moved forward (or not) by the decisions of pertinent groups that assess whether a technology's anticipated performance characteristics are likely to meet their own activity's requirements. Thus, in agreement with Mike and Alex, I have long maintained that an understanding of technological change requires that decision-making processes be modeled ( $c f$. Schiffer 1979), but I doubt that such decisions rested uniformly on "cost-benefit evaluations based on low-cost experimentation." In cases I have studied closely, decisions seem to have been based on patterns in a host of mainly qualitative performance characteristics (Schiffer 1991, 2005a, 2008a, 2011; Schiffer et al. 2003). Also, it cannot be assumed a priori that experimentation is always low cost, for determining cost - in any currency-is a case-specific empirical issue that presented difficulties to past decision makers as it does to modern researchers.

That the conflation of life cycle processes conceals consequential decisions is shown by Mike and Alex's Fig. 6, which displays the purported "time lag" between the invention and widespread adoption of several modern products. However, a genuine adoption curve begins not with the date of invention but the date when commercialization makes that product readily available to consumers. To illustrate this point, I turn to a familiar case in Fig. 6- the home radio (Schiffer 1991).

Before discussing commercialization, however, I should mention that assigning a year to any product's invention is problematic. Should we take as the date of invention the first vision of wireless communication, the first demonstration of radio frequency transmission and reception, the first technical articles, the first patents, the first prototype, or the first radios capable of use at home? Obviously, there is no right answer, for the researcher must specify which event during a product's invention 
process is of interest, and criteria for assigning a date to that event should be explicit and applied consistently. Figure 6 places the invention of radio around 1900, a date that seems arbitrary.

A host of development and manufacture decisions and activities lies between the dates of a product's invention-however defined - and its regular availability to consumers. These activities may require, for example, sizable investments of labor, materials, equipment, facilities, organization, and special expertise (Schiffer 2011). Only if people decide to invest the necessary resources, and a product is successfully manufactured, can it be adopted.

In the case of home radios, commercialization had the following basic requirements. First, people had to build broadcasting stations that could furnish programs of somewhat general interest such as news, music, and sports. Prior to the advent of commercial broadcasting in 1921, the airwaves were the province of navies and ship companies, electrical experimenters, and builders of amateur stations, especially in colleges. Reliable general interest broadcasts as such did not yet exist because potential station builders had not envisioned a robust market for programming, much less a way to make it pay. Second, people had to anticipate profits from mass producing home radio receivers before deciding to manufacture them. Prior to 1921, home receivers were mainly made by youthful enthusiasts who listened to amateur chatter, eavesdropped on maritime communications, or heard the occasional program from a college radio "station. And third", people had to develop appropriate components for assembling consumer-friendly receivers and forecast that building or enlarging factories to mass produce them might be lucrative. When these basic requirements were met in the early 1920 s, hundreds of commercial broadcasting stations were rapidly established along with hundreds of radio and component manufacturing firms. Sales of receivers by the millions followed quickly. Clearly, during the preceding decades, adoption of home radios could not have taken place.

A behavioral understanding of technological change requires that we engage and explain invention and adoption processes, and also study a technology's commercialization in its societal context (Hollenback and Schiffer 2010; Schiffer 2011). Claims about "lags" in adoption based on arbitrary invention dates and flawed "adoption" curves neither illuminate cultural transmission processes nor contribute to robust explanations of technological change.

I now turn to a brief discussion of invention: the creation of new variants. Mike and Alex insist that "variation cannot be created by selection" (their emphasis), implying that I believe the contrary. What I actually said is that "Variation in a population at one point in time is a consequence of both prior selection and varietygenerating processes" (Schiffer 1996:655). Thus, by reducing variation, prior selection affects the amount of variation present at any given time. Mike and Alex note that available variation is also reduced by drift, a process familiar to behavioral archaeologists but which has not been emphasized until recently (e.g., Hollenback and Schiffer 2010).

The behavioral concept of stimulated invention was offered to evolutionists when they had scant interest in modeling invention processes (Schiffer 1996). Since then, they have embraced the need to deal with invention, and, as Mike and Alex indicate, stimulated variation has found a place in their formulations. However, stimulated variation is just one process that can account for bursts of 
variety generation (Schiffer 2010b); others include cultural imperatives (Schiffer 1993) and component-stimulated invention (Schiffer 2008b). Incidentally, I was delighted to learn that in 1895 the biologist W.T. Thiselton-Dyer had-a century before my 1996 publication - coined the term "stimulated variation." With Internet search tools we can easily track down obscure precursors to modern constructs. By the way, Thiselton-Dyer had used "stimulated variation" in an even earlier article in Nature (Thiselton-Dyer 1888:477).

The cascade model calls attention to the invention processes that take place during the development of a complex technological system (CTS), regardless of where the idea of that system originated (Schiffer 2005b). In choosing to commercialize a CTS locally, people must solve performance problems encountered along that technology's behavioral chain, which result in sequential invention cascades. Thus, as Arnold (2007) and White and Hamilton (2009) have shown, one of the cascade model's strengths is in helping to refute simplistic diffusionist explanations.

A common belief among evolutionists is that a group's inventiveness is directly related to the size of its population, but this plausible correlation remains to be confirmed in cross-cultural tests. Even if verified, the correlation is not causal because many environmental and societal variables intervene. Although population size is generally correlated with societal complexity (e.g., Carneiro 1967; Carneiro and Tobias 1963), at a given level of complexity there is much variation in specific organizational structures and social processes. The latter, I suggest, are a major contributor to stimulated variation. Changes in organizational properties such as social differentiation, social integration, social mobility, social inequality, and leadership and governance structures can create needs for new technologies to serve specific utilitarian, symbolic, and emotive functions (Schiffer 2011). For example, when new social roles and social groups proliferate in a society, a myriad of new technologies are needed, and so inventive activities are apt to be ramped up. Likewise, an increase in social mobility may promote the "trickle down" of status markers, again creating demand for new products to replace those whose symbolic and emotive functions have been compromised by wider adoption. The scientific challenge is to understand the general relationships between population size, organizational properties, and inventiveness.

In the last section of their paper, Mike and Alex adopt a landscape model to describe a technology's design space. This approach might also be employed in discussing alternative paths in behavioral models of the design process (Schiffer 2010a, 2011; Schiffer and Skibo 1997; Skibo and Schiffer 2001, 2008). However, the concept of "optimal design" is problematic because, as noted above, many performance characteristics are qualitative, and what is optimal in one activity context may not be optimal in another. Indeed, behavioral models of design perform adequately without employing the concept of optimality.

Mike and Alex have coupled stimulated variation, and the cascade model of invention processes to an evolutionary archaeology whose cultural transmission models build on tenets of diffusion theory. Rejecting these tenets, I suggest that the models, which in the invention-innovation dichotomy also conflate a technology's life cycle processes, require rethinking. Yet, the behavioral models of learning and teaching frameworks based on experiments and ethnoarchaeology are less abstract and less general than evolutionary models. Perhaps a convergence in models of 
cultural transmission is possible if we give attention to specific social processes that affect the life cycles of technologies.

Robert L. Kelly

Focusing on the Binford-Schiffer "debates" of the 1970s and 1980s, Bob's thoughtful and provocative paper raises questions about how specific programs or ideas are reproduced in a discipline. He takes an evolutionary tack in comparing the formation process (Schiffer) and the middle-range theory (Binford) programs. Following O'Brien et al. (2005), Bob begins with the premise that the latter outcompeted the former and furnishes an eminently disputable explanation (I should note that O'Brien et al. 2005 discussion is highly nuanced, but I do not wish to engage here in textual exegesis).

As Bob notes, the middle-range theory and formation process programs have similar goals: to take into account sources of variability - cultural and environmental - that create the archaeological record. However, the bulk of Binford's writings deals with mobile hunter-gatherers and mine treat mainly sedentary societies. Accordingly, I believe that both programs are successful variants, each competing in its own substantive domain against unsophisticated approaches that do not explicitly handle formation processes. And both programs have generated an enormous amount of productive research, bringing closer our ability to infer reliably the behavioral and organizational properties of past societies. Binford's seminal books, Bones (Binford 1981) and Nunamiut Ethnoarchaeology (Binford 1978) have garnered many more citations than any of mine, but both Behavioral Archaeology (Schiffer 1976) and Formation Processes of the Archaeological Record (Schiffer 1987) have a respectable showing in Google scholar.

In terminology, however, there is head-on competition, and it does appear that Binford's catchy phrase - "middle-range theory" (borrowed from sociologist Robert Merton)—won out over my less euphonious correlates, c-transforms, and n-transforms. Some archaeologists regard the latter terms as clumsy, but they precisely delimit epistemologically important domains of empirical processes. Binford never developed a fully general theory of formation processes, saw no need to distinguish among these domains, and conflated correlates and c-transforms. On the rare occasions today when I write abstractly about inference and formation processes, I retain the original terms (e.g., Schiffer 2010a). Perhaps Binford's terminology did become more popular, but even that claim invites evaluation with relevant evidence from the literature. The adoption of specific terms can also be a rhetorical strategy to signal one's affiliation with particular people and programs, yet these terms and drive-by citations may be unrelated to the actual work being reported.

Without conceding that Binford's program enjoyed greater success, I now consider in turn the causal factors that Bob assesses. Because both Binford and I have done little fieldwork and almost none in recent decades, Bob dismisses this factor. (Nonetheless, some archaeologists may use the fieldwork factor as a rationale to ignore both programs, echoing the earlier treatment of W.W. Taylor.) Bob also places little weight on the charisma factor: although observing that I have a charisma deficit, he does not believe it is decisive. However, Binford's great charisma had effects wherever he taught, for he acquired adherents to his program by the dozens, many of whom are now important contributors to the discipline, reproducing and embellishing his ideas and terminology. He was an enormously talented "recruiter" 
(cf. O'Brien et al. 2005). Indeed, I continue to advance the part of Binford's agenda dedicated to making archaeology more scientific, which I learned from him while an undergraduate at UCLA.

Bob places major weight on the argument that Binford's program has been more successful because it was "attached to substantive debates about prehistory," whereas I have been "less involved." Binford had a knack for tackling the "big" questionsthose that resonated widely throughout the discipline - such as the origins of agriculture, Mousterian assemblage variability, and hunting versus scavenging in the Lower Paleolithic. Moreover, as Bob suggests, Binford's theoretical and methodological arguments were embedded in his contributions to these debates. Although I did not address the "big" questions, colleagues and I grappled with substantive problems of interest to prehistorians of the American Southwest, such as Hohokam chronology (Schiffer 1982, 1986, 1987), the pit house-to-pueblo transition (McGuire and Schiffer 1983), Hill's classic studies of social organization at Broken K Pueblo (Schiffer 1987, 1989; Skibo et al. 1989), the formation processes of house floors and fills (LaMotta and Schiffer 1999; Schiffer 1983, 1985, 1987; Seymour and Schiffer 1987), and the design of large-scale archaeological surveys (Schiffer et al. 1978; Schiffer and Wells 1982). These studies demonstrated new ways to observe, think about, and analyze the prehistoric record, but none captivated the entire discipline. I also wonder whether some of the "big" issues Binford took up, particularly Mousterian variability and Lower Paleolithic subsistence, became big by virtue of his involvement. Perhaps a brilliant and charismatic theorist with an impressive record of accomplishments possesses the social power to designate which questions are significant. I leave the examination of these issues to future historians of archaeology employing a rigorous analytical framework and acquiring relevant evidence such as oral history, citations analysis, and archival materials.

One factor that Bob does not mention is that Binford had a decade-long head start in creating his persona as an archaeological theorist, assuming that we take Binford (1962) and Schiffer (1972) as starting points. By the time I began publishing on formation processes, "new" or "processual" archaeology had already transformed the discipline, and Binford had become a major authority figure. In view of his established credibility as a theorist, many young researchers might have turned to him for guidance in matters of inference and formation processes.

I appreciate Bob's kind words about my forays into electrical technologies. Admittedly, few archaeologists are interested in such technologies, per se, but these projects have led to models and heuristics applicable to prehistory (Schiffer 2011 is a recent synthesis). Decades after we called attention to the research potential of modern material culture studies (Reid et al. 1975), the continuing antipathy to them in the United States remains an enigma to me.

I concede Bob's point that prehistorians have little interest in theory, per se. Many will turn to theory if it promises to help solve substantive problems - and that is as it should be. Nonetheless, it would appear that there is a tiny niche for theorists who want to create a new behavioral science on an archaeological foundation that is dedicated to studying the relationships between people and their material things.

Linda S. Cordell

Responding to Linda's paper is difficult because it does not follow the Forum's instruction to be critical, and so I resort at times to personal anecdote. 
The Grasshopper-Chavez Pass Debate is easily dispensed with. I did not take part, and the Grasshopper researchers ably defended their interpretations (e.g., Reid 1999; Reid and Whittlesey 1989, 2005). However, in the Grasshopper researchers' response to Cordell et al. (1987), I did provide a section about the formation of de facto refuse in pueblo rooms (Reid et al. 1989). An aside: it is highly unusual for a researcher to express deep regrets about the tone and content of an earlier paper, but Linda is not your usual colleague. Some of us never admit mistakes, much less do so with such grace.

Cordell et al. (1987) did raise one general issue - the role of the culture construct in archaeology - that remains contentious. I am convinced that for large-scale questions, such as the causes of long-term behavioral and organizational change, the concept of culture per se plays no explanatory role. Moreover, alternative theoretical frameworks that include cognitive modeling can help to explain human behavior on fine-grained scales (e.g., Schiffer and Miller 1999). Yet, I know that many researchers I respect and admire, including Linda, may disagree. Perhaps if faced with compelling arguments and evidence, I might soften my stance.

More than three decades ago, Fred Plog and I visited England, driving aroundon the "wrong" side of roads - in a rental car that was barely large enough to hold us and our luggage. Fred was a dear friend, though we disagreed on almost all matters archaeological, including the best way to build a sound Hohokam chronology. We staged lengthy-some would say tedious-debates at five major universities including Cambridge, already home to a strident antipathy to processual and behavioral archaeologies. Audiences at UK universities, we believed, would be receptive to the demonstration that even theorists could handle evidence in solving long-standing problems in prehistory. We were wrong. As comments filtered back to us after our return to the United States, we learned that UK archaeologists, especially those at Cambridge, cared nothing about the prehistory of North America, and were disappointed at our failure to present new theories. Even so, our UK colleagues treated us well, and I retain very fond memories of this trip - my first across the Atlantic. Despite our differing theoretical orientations, Fred and I remained friends until his untimely passing at age 47.

What would have happened had I accepted the offer in 1975 to join the University of New Mexico faculty as Director of the Office of Contract Archaeology? My lack of managerial skills most likely would have led OCA to financial disaster.

Stephen S. Plog

As Steve notes, our friendship began in the summer of 1968 at Vernon. Although spending much time in the kitchen and clearing tables in the dining room, Steve was unable to improve the food, which on a good day was wretched.

I find little to dispute in Steve's paper, but his discussion gives me an opportunity to pontificate somewhat on the definition of the discipline and on the place of (experimental) laws in archaeological research.

Steve notes that many archaeologists do not accept the behavioral definition of archaeology, the study of relationships (or interactions) between people and artifacts in all time and all places. Steve and others entered archaeology, he suggests, with an interest in "people and the many dimensions of human societies." I am also interested in people and societies, but the immediate cause of human traces in the archaeological record is behavior-i.e., people-artifact interactions. Thus, a concern 
with these interactions is a precondition for crafting sound inferences and explanations because every social inference ultimately rests upon inferred regularities of human behavior. Some archaeologists improve the conceptual tools for understanding people-artifact interactions, some use available tools to address substantive questions, and some do both. I see many virtues in a division of scholarly labor along these lines, but it can lead to misunderstandings.

The study of people-artifact interactions is fundamental to the archaeological research process, and it is - as Steve recognizes - potentially much more. Beginning with the earliest publications (Reid et al. 1975; Schiffer 1975a, 1976), we asserted that this focus enables us to build a new behavioral science, one that can eventually yield productive social theory. This opportunity has not been fully exploited, but the tangible accomplishments of ethnoarchaeology, modern material culture studies, and varied theoretical explorations demonstrate that this stance is more than posturing. My contributions, for example, include an artifact-based theory of human communication (Schiffer and Miller 1999) and a framework of generalizations and heuristics for studying any technological change in any society (Schiffer 2011). Steve correctly points out that there are many paths to social theory, but with our conceptual tools and our access to evidence that spans the entire human past, only we archaeologists can tread the path to social theory that begins with the study of people-artifact interactions.

The use of the term "law" in many behavioral publications has admittedly been an obstacle to some archaeologists who, unlike Steve, have ignored the nuances of definition and application of the term. Experimental laws - generalizations that have a large empirical content-are the workhorse of every science, including archaeology. All of our textbooks on specific technologies, on formation processes, and on fieldwork, for example, contain many such generalizations. In a science of human behavior, there are, in addition to theory, two kinds of lower level generalizations. Experimental laws (probabilistic, statistical, etc.) describe general processes; as such they lack time-space boundary conditions. An experimental law, I emphasize, is not a "universal" law (a chimera at best), for it applies only when the substantive boundary conditions are met, such as "in cities" or "in bipolar flaking" or "in maintained activity areas." Empirical generalizations (sometimes called "local expertise") describe contingent processes restricted to given times and places, such as a society- or group-specific behavior pattern, as in "the Hohokam made red-onbuff pottery." As Steve reminds us, archaeology depends on both kinds of generalizations. Archaeologists who deny the possibility of formulating laws of human behavior betray narrow scholarship; moreover, they surely do not recognize the implications of their own position, for without such generalizations the human past is inaccessible. Having reiterated my commitment to the concept of experimental laws, I concede that in recent years I have used the term "law" less often.

Diane Gifford-Gonzalez

Diane observes that our researches have followed parallel tracks as we strove to perfect archaeology's inferential tools. Although our empirical foci have differed as have our jargons, I see no real differences in basic approaches. Everyone in science uses analogical arguments and relies to some extent on uniformitarianism, and modern archaeology would be inconceivable without actualist research carried out in experimental and ethnoarchaeological contexts. I also agree with Diane's statement that "the remains of any organism, wild or domestic, once it has passed through 
human hands, is an artifact" (cf. Schiffer and Miller 1999) (Incidentally, questions about the adoption of agriculture have not been productively framed. It is not just about the plants and animals; it is also about adoption of the technologies employed throughout those plants' and animals' entire life histories in systemic context, but that is another story ( $c f$. LaMotta and Schiffer 2001)).

Some version of the life history framework is widely used in archaeological inference, whether flow models or behavioral chains or chaînes opératoires (the latter are life histories truncated after manufacture). I suggest that the applicability of a life history framework does not depend on the kind of material or technology being studied - animate or inanimate, reductive or additive, ancient or modern. Behavioral chain analysis (Schiffer 1975b), for example, was offered as a general heuristic for inferring activities in the life history of any artifact (as a necessary step in inferring the activities that occurred in a structure). In this mode of analysis, the focus is on the likely "outputs" to the archaeological record created by the performance of specific activities along an entity's behavioral chain. Drawing on preprints of my paper, researchers first applied behavioral chain analysis to yucca (Stier 1975) and cotton (Magers 1975) from Antelope House, a cliff dwelling in northeastern Arizona. Behavioral chain analysis is equally applicable to faunal remains, ceramics, chipped and ground stone, metals, even architecture.

After reading some of my works on electrical technologies, Diane pondered an "intriguing mystery," how far am I "willing to assume behavioral uniformities in the past?" My books on electrical technologies are works of history that employ behavioral generalizations and heuristics, often implicitly. Owing to a dearth of relevant general principles, I incorporated empirical generalizations into explanations. For example, in discussing why middle class American families, which could afford to buy and maintain just one car, bought gasoline-powered and not electric cars in the period 1900-1920, I pointed out that these vehicle types were not functionally equivalent: the gasoline car was suitable for touring during the summer, the electric excelled in urban travel year round (Schiffer et al. 1994a). Thus, the acquisition of only one type of car necessarily precluded some activities. The latter was highly gendered, in that men favored touring, women preferred travel in town.

Presently, we lack experimental laws to explain why middle class families favored men's leisure activities over women's social and domestic activities. Thus, the explanation invoked an empirical generalization: the patriarchal structure of traditional middle class families enabled men, who held the purse strings for such purchases, to privilege their own activities. Upper class families, however, could easily buy both kinds of cars - and thousands did, including the Fords and the Edisons, enabling all automobile-related activities. This pattern of class differences in adoption enabled me to suggest a law-like hypothesis. Originally called the "Imelda Marcos hypothesis" (Schiffer 1995), its latest formulation goes somewhat as follows: wealthier social units tend to enhance favored activities by acquiring many functionally specialized artifacts (Schiffer 2011). Together, this hypothesis and the empirical generalization render intelligible the adoption patterns of early electric cars. On the basis of these electrical history projects, I have crafted additional generalizations and heuristics and made them known to archaeologists (cited above).

Trotting out the electric car example (yet again) allows me to admit that I do not know how far we can push the effort to craft general behavioral principles such as 
experimental laws. As an optimist, I believe that continued research will pay rich nomothetic dividends, but explaining behavioral change may always require a mix of general principles and empirical generalizations that respect historical contingency and group-specific behavior patterns.

Diane's case studies call attention to the wide range of social inferences that can be obtained through the intensive analysis of materials. She and her colleague Habicht-Mauche and their students have undertaken significant studies that underscore the signal value of laboratory analyses. These kinds of projects, which are becoming much more common and now crosscut every theoretical orientation, have done much to raise the visibility and prestige of skilled analysts. After all, only in the laboratory do archaeological data become evidence of past behaviors.

Laboratory analyses often employ experimental laws obtained through archaeological experiments (Schiffer and Skibo 1987). In the Laboratory of Traditional Technology, studies of ceramics yielded experimental laws (correlates) on, for example, the effects of surface treatments on a variety of use-related performance characteristics (Schiffer and Skibo 1997; Schiffer et al. 1994b). Another important result was that of clarifying the crucial distinction between material properties and performance characteristics (Schiffer 2003; Skibo and Schiffer 2008). A material property is a quality of the material itself, as defined by the researcher and assessed in a laboratory test carried out on specimens carefully prepared according to a rigid protocol. Thus, thermal conductivity is a material property. A performance characteristic is a relational construct that denotes the ability of some entity (artifact, person, etc.) to carry out a specific interaction in a real-world, not laboratory, activity. Thus, heating effectiveness is the rate at which a vessel-in a given activity-heats its contents (Schiffer 1990), which may or may not depend on the vessel's thermal conductivity. Experiments to assess performance characteristics mimic real-world activities, such as heating a vessel over an open fire. Clearly, a performance characteristic is a relational construct that applies to any behavioral capability of any entity. Both material properties and performance characteristics play pivotal roles in behavioral studies of technology.

As Diane notes, for more than two decades I edited annual volumes on method and theory, enabling archaeologists of every theoretical persuasion to air their views. The editor's job, as I saw it, was to help an author transform a promising draft into an excellent publication. I relied extensively on peer reviews (six to eight per paper) to supply constructive comments, but I always read the paper and made the final decision, publishing those that I believed might be useful even if they had garnered some negative reviews. Many editors today delegate decision making to referees, often rejecting a paper with one negative review; surely this is a route to mediocrity. The considerable time I put into editing was well worth it, for I take special pride in having published the first major paper of many young scholars, even graduate students, who eventually rose to prominence.

\section{Concluding Remarks}

And what do I make of this experiment in communication? Colleagues familiar with my research and teaching know that I value critique as highly as creativity, for both are essential to progress in science. Although these forum papers were not uniformly 
critical, they gave me the opportunity to address several long festering issues, to reiterate and clarify some positions, and to present a few views not published previously. Most importantly, the criticisms meet the highest standard of scholarly discourse, and so can serve as a model for younger colleagues. We can disagree agreeably, though it is sometimes difficult (as in the notorious debates between Binford and me about formation processes). I had fun at the SAA Forum and in composing this response, but only the reader can judge whether this experiment was successful.

\section{References}

Arnold, J. (2007). Credit where credit is due: The history of the chumash oceangoing plank canoe. American Antiquity, 72, 196-209.

Binford, L. R. (1962). Archaeology as anthropology. American Antiquity, 28, 217-225.

Binford, L. R. (1978). Nunamiut ethnoarchaeology. New York: Academic.

Binford, L. R. (1981). Bones: Ancient men and modern myths. New York: Academic.

Carneiro, R. L. (1967). On the relationship between size of population and complexity of social organization. Southwestern Journal of Anthropology, 23, 234-243.

Carneiro, R. L., \& Tobias, S. F. (1963). The application of scale analysis to the study of cultural evolution. New York Academy of Sciences, Transactions, 26, 196-207.

Cordell, L., Upham, S., \& Brock, S. (1987). Obscuring cultural patterns in the archaeological record: A discussion from Southwestern archaeology. American Antiquity, 52, 565-577.

Hollenback, K. L. (2010). Landscapes. In M. B. Schiffer (Ed.), Behavioral Archaeology: Principles and Practice (pp. 186-193). London: Equinox.

Hollenback, K. L., \& Schiffer, M. B. (2010). Technology and material life. In D. Hicks \& M. Beaudry (Eds.), The Oxford handbook of material culture studies (pp. 313-332). Oxford: Oxford University Press.

LaMotta, V., \& Schiffer, M. B. (1999). Formation processes of house floor assemblages. In P. M. Allison (Ed.), The archaeology of household activities (pp. 19-29). London: Routledge.

LaMotta, V., \& Schiffer, M. B. (2001). Behavioral Archaeology: Towards a new synthesis. In I. Hodder (Ed.), Archaeological theory today (pp. 14-64). Cambridge: Polity Press.

Magers, P. (1975). The cotton industry at Antelope house. Kiva, 41, 39-47.

McGuire, R. H., \& Schiffer, M. B. (1983). A theory of architectural design. Journal of Anthropological Archaeology, 2, 277-303.

O’Brien, M. J. (Ed.). (2008). Cultural transmission and archaeology: Issues and case studies. Washington: Society for American Archaeology.

O’Brien, M. J., Lyman, R. L., \& Schiffer, M. B. (2005). Archaeology as a process: Processualism and its progeny. Salt Lake City: University of Utah Press.

Reid, J. J. (1999). The grasshopper-chavez pass debate: Existential dilemmas and archaeological discourse. In S. M. Whittlesey (Ed.), Sixty years of mogollon archaeology (pp. 13-22). Tucson: SRI Press.

Reid, J. J., \& Whittlesey, S. (1989). The individual, the community, and social organization: Issues of evidence and inference justification. In S. MacEachern, D. Archer, \& R. Garvin (Eds.), Households and communities (pp. 227-234). Calgary: University of Calgary.

Reid, J. J., \& Whittlesey, S. (2005). Thirty years into yesterday: A history of archaeology at grasshopper pueblo. Tucson: University of Arizona Press.

Reid, J. J., Schiffer, M. B., \& Rathje, W. L. (1975). Behavioral Archaeology: Four strategies. American Anthropologist, 77, 864-869.

Reid, J. J., Schiffer, M. B., Whittlesey, S. M., Hinkes, M. J., Sullivan, A. P., Downum, C. E., et al. (1989). Perception and interpretation in Southwestern archaeology: comment on Cordell, Upham, and Brock. American Antiquity, 54, 802-814.

Schiffer, M. B. (1972). Archaeological context and systemic context. American Antiquity, 37, 156-165.

Schiffer, M. B. (1975a). Archaeology as behavioral science. American Anthropologist, 77, 836-848.

Schiffer, M. B. (1975b). Behavioral chain analysis: activities, organization, and the use of space. In chapters in the prehistory of eastern Arizona, IV. Fieldiana: Anthropology, 65, 103-119.

Schiffer, M. B. (1976). Behavioral Archaeology. New York: Academic. 
Schiffer, M. B. (1979). A preliminary consideration of behavioral change. In C. Renfrew \& K. Cooke (Eds.), Transformations: Mathematical approaches to culture change (pp. 353-368). New York: Academic.

Schiffer, M. B. (1982). Hohokam chronology: An essay on history and method. In R. H. McGuire \& M. B. Schiffer (Eds.), Hohokam and Patayan: Prehistory of Southwestern Arizona (pp. 299-344). San Diego: Academic.

Schiffer, M. B. (1983). Toward the identification of formation processes. American Antiquity, 48, 675-706.

Schiffer, M. B. (1985). Is there a "Pompeii premise" in archaeology? Journal of Anthropological Research, $41,18-41$.

Schiffer, M. B. (1986). Radiocarbon dating and the "Old Wood" problem: The case of the hohokam chronology. Journal of Archaeological Science, 13, 13-30.

Schiffer, M. B. (1987). Formation processes of the archaeological record. Albuquerque: University of New Mexico Press.

Schiffer, M. B. (1988). The structure of archaeological theory. American Antiquity, 53, 461-485.

Schiffer, M. B. (1989). Formation processes of Broken K Pueblo: Some hypotheses. In R. D. Leonard \& G. T. Jones (Eds.), Quantifying diversity in archaeology (pp. 37-58). Cambridge: Cambridge University Press.

Schiffer, M. B. (1990). The influence of surface treatment on heating effectiveness of ceramic vessels. Journal of Archaeological Science, 17, 373-381.

Schiffer, M. B. (1991). The portable radio in American life. Tucson: University of Arizona Press.

Schiffer, M. B. (1993). Cultural imperatives and product development: The case of the shirt-pocket radio. Technology and Culture, 34, 98-113.

Schiffer, M. B. (1995). Social theory and history in Behavioral Archaeology. In J. M. Skibo, W. H. Walker, \& A. E. Nielsen (Eds.), Expanding archaeology (pp. 22-35). Salt Lake City: University of Utah Press.

Schiffer, M. B. (1996). Some relationships between behavioral and evolutionary archaeologies. American Antiquity, 61, 643-662.

Schiffer, M. B. (2003). Properties, performance characteristics and behavioural theory in the study of technology. Archaeometry, 45, 169-172.

Schiffer, M. B. (2005a). The electric lighthouse in the nineteenth century: Aid to navigation and political technology. Technology and Culture, 45, 275-305.

Schiffer, M. B. (2005b). The devil is in the details: The cascade model of invention processes. American Antiquity, 70, 485-502.

Schiffer, M. B. (2008a). Power struggles: Scientific authority and the creation of practical electricity before Edison. Cambridge: MIT Press.

Schiffer, M. B. (2008b). A cognitive analysis of component-stimulated invention: Electromagnet, telegraph, and the capitol dome's electric gas-lighter. Technology and Culture, 49, 376-398.

Schiffer, M. B. (2008c). Transmission processes: A behavioral perspective. In M. J. O’Brien (Ed.), Cultural transmission and archaeology: Issues and case studies (pp. 102-111). Washington: Society for American Archaeology.

Schiffer, M. B. (2010a). Behavioral Archaeology: Principles and practice. London: Equinox.

Schiffer, M. B. (2010b). Can archaeologists study processes of invention? In M. J. O'Brien \& S. J. Shennan (Eds.), Innovation in cultural systems: Contributions from evolutionary anthropology (pp. 235-249). Cambridge: MIT Press.

Schiffer, M. B. (2011). Studying technological change: A behavioral approach. Salt Lake City: University of Utah Press.

Schiffer, M. B., \& Miller, A. R. (1999). The material life of human beings: Artifacts, behavior, and communication. London: Routledge.

Schiffer, M. B., \& Skibo, J. M. (1987). Theory and experiment in the study of technological change. Current Anthropology, 28, 595-622.

Schiffer, M. B., \& Skibo, J. M. (1997). The explanation of artifact variability. American Antiquity, 62, $27-50$.

Schiffer, M. B., \& Wells, S. (1982). Archaeological surveys: Past and future. In R. H. McGuire \& M. B. Schiffer (Eds.), Hohokam and Patayan: Prehistory of Southwestern Arizona (pp. 345-383). San Diego: Academic.

Schiffer, M. B., Sullivan, A. P., \& Klinger, T. C. (1978). The design of archaeological surveys. World Archaeology, 10, 1-28.

Schiffer, M. B., Butts, T. C., \& Grimm, K. K. (1994a). Taking charge: The electric automobile in America. Washington: Smithsonian Institution Press.

Schiffer, M. B., Skibo, J. M., Boelke, T. C., Neupert, M. A., \& Aronson, M. (1994b). New perspectives on experimental archaeology: Surface treatments and thermal response of the clay cooking pot. American Antiquity, 59, 197-217. 
Schiffer, M. B., Skibo, J. M., Griffitts, J., Hollenback, K., \& Longacre, W. A. (2001). Behavioral Archaeology and the study of technology. American Antiquity, 66, 729-738.

Schiffer, M. B., Hollenback, K. L., \& Bell, C. L. (2003). Draw the lightning down: Benjamin Franklin and electrical technology in the age of enlightenment. Berkeley: University of California Press.

Seymour, D. J., \& Schiffer, M. B. (1987). A preliminary analysis of pithouse assemblages from Snaketown, Arizona. In S. Kent (Ed.), Method and theory for activity area research: An ethnoarchaeological approach (pp. 549-603). New York: Columbia University Press.

Skibo, J. M., \& Schiffer, M. B. (2001). Understanding artifact variability and change: A behavioral framework. In M. B. Schiffer (Ed.), Anthropological perspectives on technology (pp. 139-149). Albuquerque: University of New Mexico Press.

Skibo, J. M., \& Schiffer, M. B. (2008). People and things: A behavioral approach to material culture. New York: Springer.

Skibo, J. M., Schiffer, M. B., \& Kowalski, N. (1989). Ceramic style analysis in archaeology and ethnoarchaelogy. Journal of Anthropological Archaeology, 8, 388-409.

Stier, F. (1975). Behavioral chain analysis of yucca remains at antelope house. Kiva, 41, 57-64.

Thiselton-Dyer, W. T. (1888). Opening address, section D, biology. Nature, 38, 473-480.

Walker, W. H., \& Schiffer, M. B. (2006). The materiality of social power: The artifact-acquisition perspective. Journal of Archaeological Method and Theory, 13, 67-88.

White, J. C., \& Hamilton, E. G. (2009). The transmission of early bronze technology to Thailand: New perspectives. Journal of World Prehistory, 22, 357-397. 